\title{
Magnetic and conductive liquid metal gel
}

Salma Merhebi ${ }^{1}$, Mohannad Mayyas ${ }^{1}$, Roozbeh Abbasi ${ }^{1}$, Michael J. Christoe ${ }^{1}$, Jialuo Han ${ }^{1}$, Jianbo Tang ${ }^{1}$, Md Arifur Rahim ${ }^{1}$, Jiong Yang ${ }^{1}$, Thiam Teck Tan' ${ }^{2}$, Dewei Chu ${ }^{2}$, Jin Zhang 3 , Sean Li ${ }^{2}$, Chun H. Wang ${ }^{3}$, Kourosh Kalantar-Zadeh ${ }^{{ }^{*}}$, Francois-Marie Allioux ${ }^{{ }^{*}}$

${ }^{1}$ School of Chemical Engineering, University of New South Wales (UNSW), Sydney, NSW 2052, Australia

${ }^{2}$ School of Materials Science and Engineering, UNSW, Sydney, NSW 2052, Australia

${ }^{3}$ School of Mechanical and Manufacturing Engineering, UNSW, Sydney, NSW 2052, Australia

*Emails: k.kalanatar-zadeh@unsw.edu.au and f.allioux@unsw.edu.au 

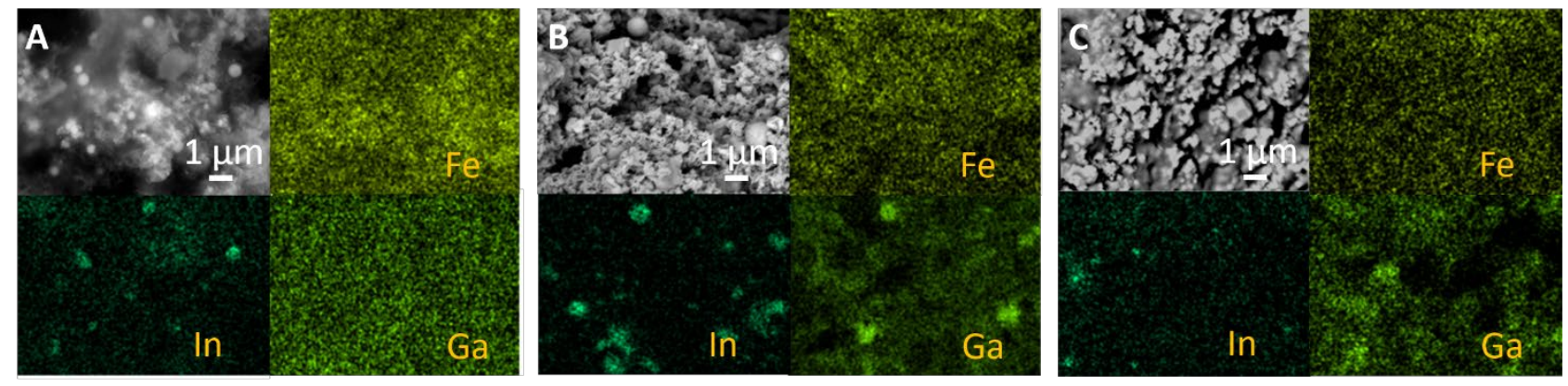

Figure S1. SEM/EDS mapping of the gels. A) 2 wt\% PVA and 1 w:w magnetic NPs:EGaln. B) 2 wt\% PVA and $4 \mathrm{w}: w$ magnetic NPs:EGaln. C) 4 wt\% PVA and 4 w:w magnetic NPs:EGaln.

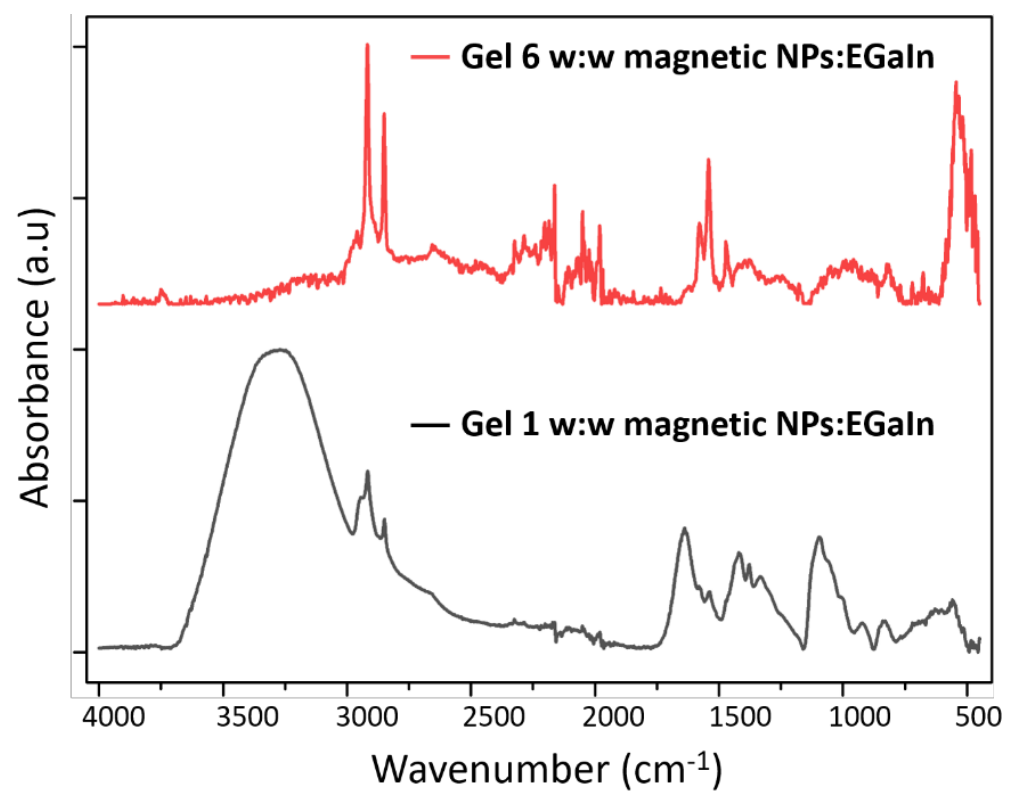

Figure S2. FTIR spectra of the gels produced with 2 wt\% PVA and 1 or 6 w:w magnetic NPs:EGaln ratio. 

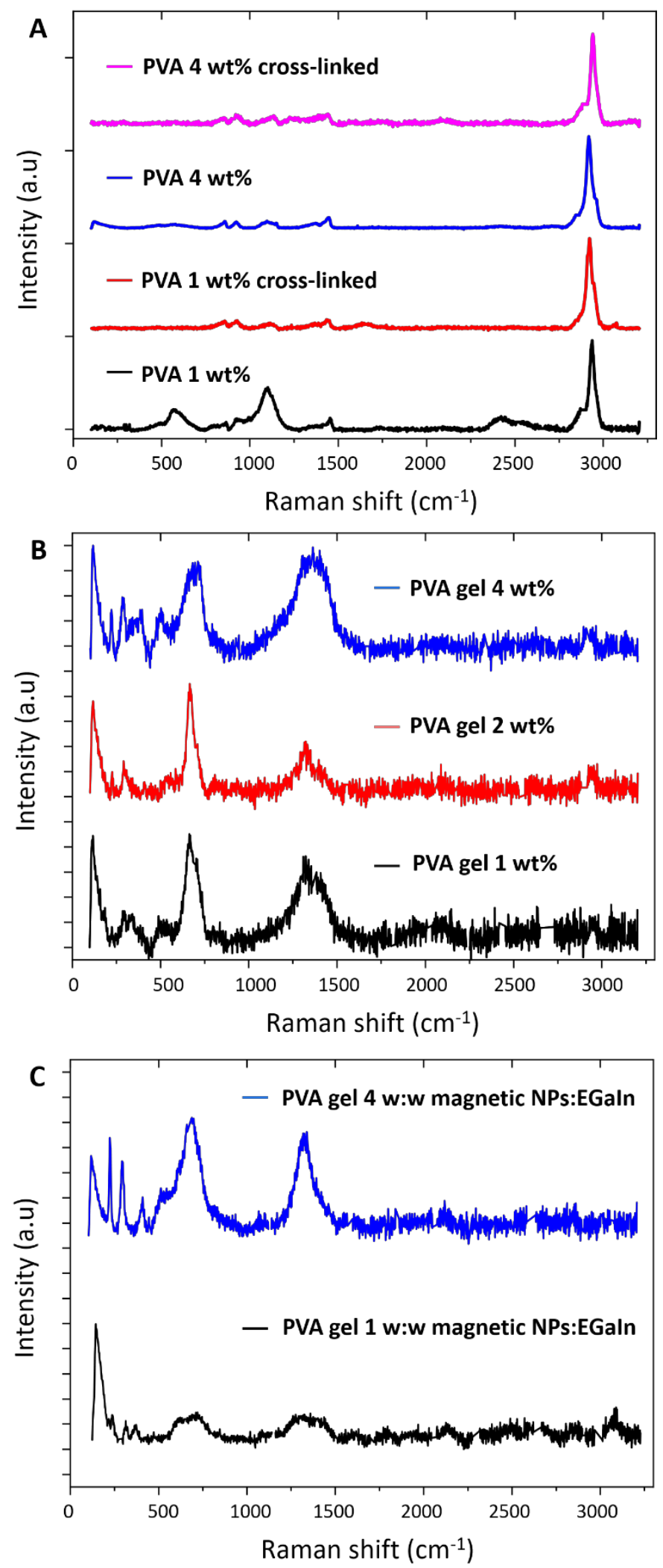

Figure S3. Raman Spectra. A) PVA and cross-linked PVA at 1 and 2 wt\%. B) Gel with a PVA content of 1, 2 and $4 \mathrm{wt} \%$. C) Gel with 1 and $4 \mathrm{w}: \mathrm{w}$ ration of magnetic NPs:EGaln. 

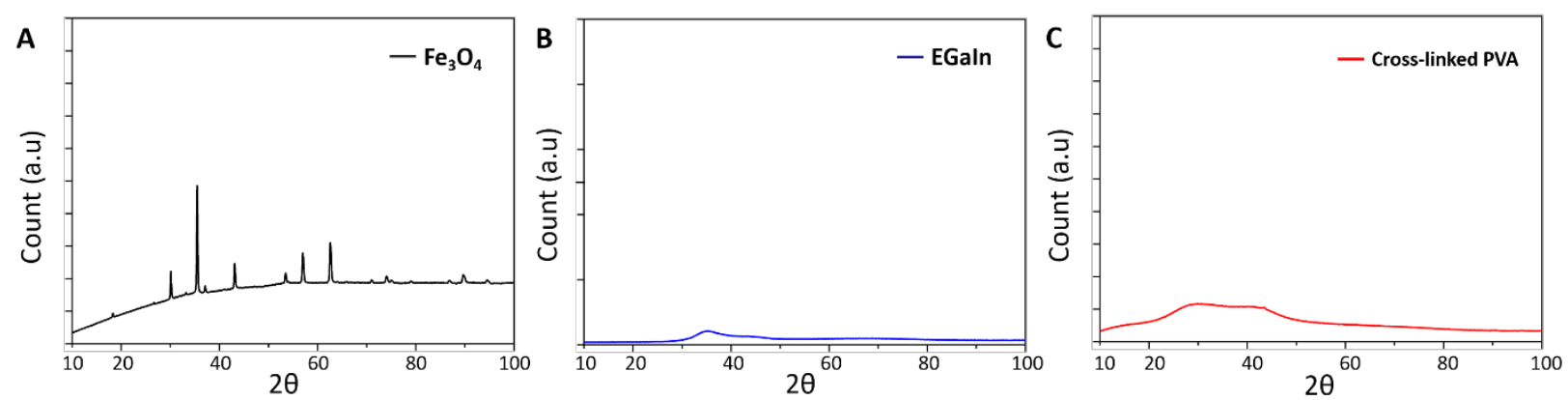

Figure S4. XRD patterns. A) $\mathrm{Fe}_{3} \mathrm{O}_{4}$ nanoparticles. B) EGaln liquid alloy. C) Plain cross-linked PVA.

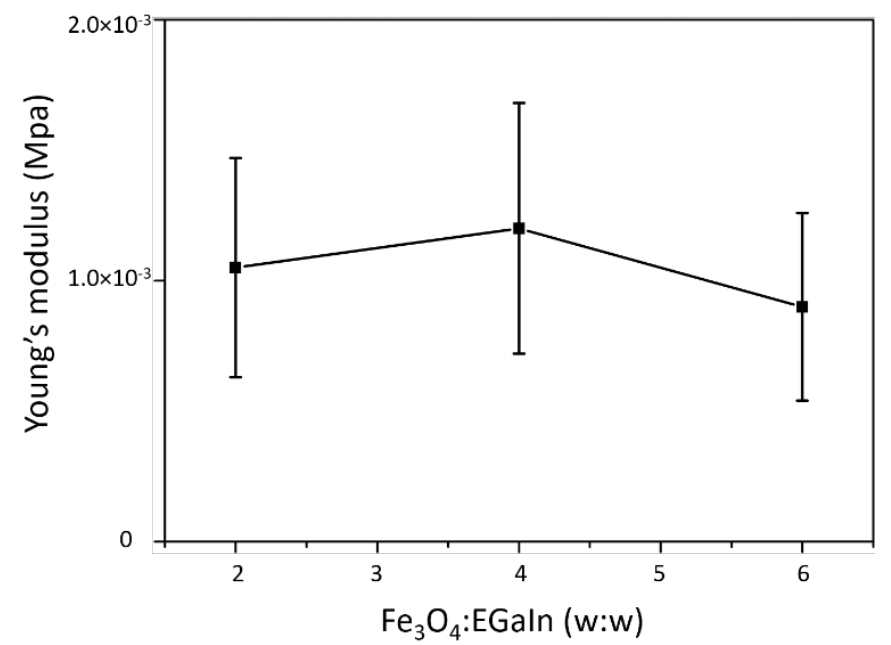

Figure S5. Young's modulus of the gels with 1, 4 and $6 \mathrm{w}$ :w ratio of magnetic NPs:EGaln. 


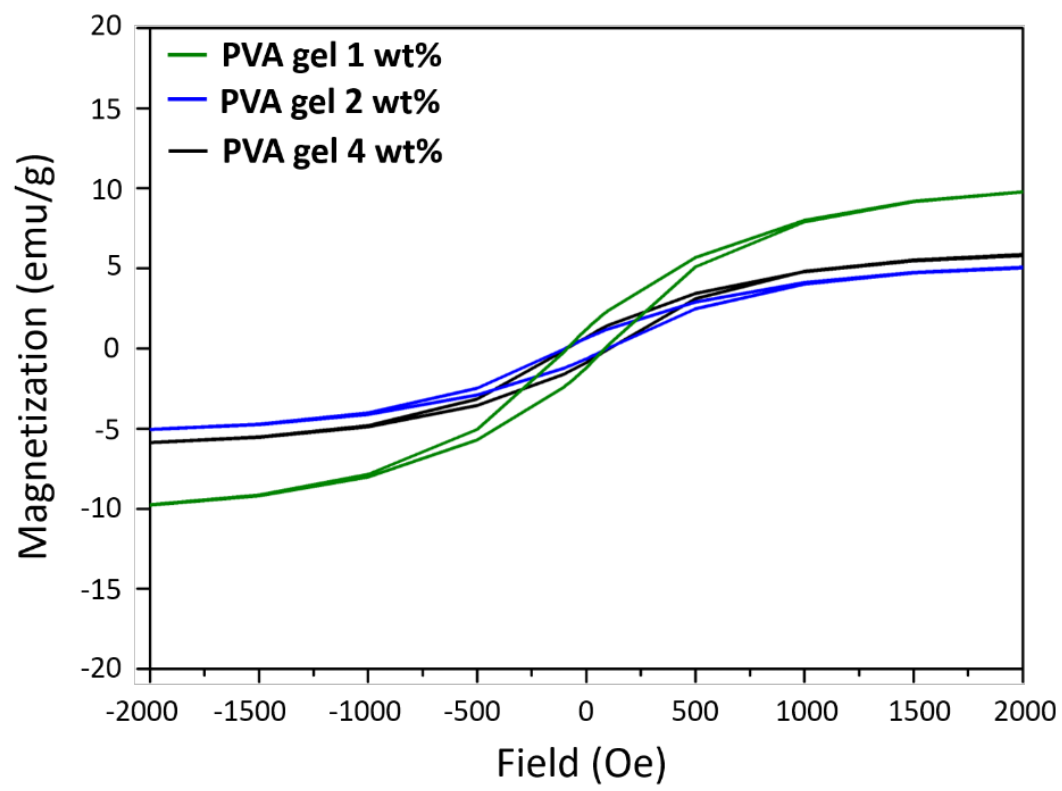

Figure S6. Magnetization susceptibility of the gels as a function of the PVA concentration, magnetic NPs:EGaln ratio fixed at 4:1 w:w. 
Table S1. Mechanical properties of the 4 wt\% PVA gels

\begin{tabular}{|c|c|c|c|}
\hline $\begin{array}{c}\text { Sample name } \\
\text { and condition }\end{array}$ & $\begin{array}{c}\text { Young's modulus } \\
\text { (MPa) }\end{array}$ & $\begin{array}{c}\text { Tensile strength at } \\
\text { breaking point } \\
\text { (MPa) }\end{array}$ & $\begin{array}{c}\text { Elongation at } \\
\text { breaking point } \\
\text { (\%) }\end{array}$ \\
\hline $\begin{array}{c}\text { Gel 4 wt\% } \\
30 \% \text { dry }\end{array}$ & $4.2 \pm 1.3 \times 10^{-3}$ & $0.24 \pm 0.05$ & $338 \pm 78$ \\
\hline Gel 4 wt\% & $3.0 \pm 1.6 \times 10^{-3}$ & $0.05 \pm 0.01$ & $180 \pm 41$ \\
\hline Gel 4 wt\% after & $4.0 \pm 1.2 \times 10^{-3}$ & $0.04 \pm 0.01$ & $180 \pm 41$ \\
\hline self-healing & & & \\
\hline
\end{tabular}

Equation S1. Preparation of the borax solution and hydrolysis mechanism. ${ }^{1}$

Borax, or sodium tetraborate decahydrate $\left(\mathrm{Na}_{2} \mathrm{~B}_{4} \mathrm{O}_{7} \cdot 10 \mathrm{H}_{2} \mathrm{O}\right)$, hydrolyses in water to form boric acid as showed in (1) to (2) and ultimately forms a stable borate ion (3) in solution at a pH close to nine.

(1) $\mathrm{B}_{4} \mathrm{O}_{7}^{2-}(a q)+\mathrm{H}_{2} \mathrm{O}(l) \rightarrow \mathrm{HB}_{4} \mathrm{O}_{7}^{-}(a q)+\mathrm{OH}^{-}(a q)$

(2) $\mathrm{HB}_{4} \mathrm{O}_{7}^{-}(a q)+5 \mathrm{H}_{2} \mathrm{O}(l)+2 \mathrm{H}^{+}(a q) \rightarrow 4 \mathrm{H}_{3} \mathrm{BO}_{3}(a q)$

(3) $B(O H)_{3}(a q)+H_{2} O(l) \rightarrow B(O H)_{4}^{-}(a q)+H^{+}(a q)$

\section{REFERENCE}

(1) Tan, X. M.; Huang, N. Y.; Xie, H. Q. Complexation between borate ion and hydroxyl groups of phenol-formaldehyde resol resin. J Wuhan Univ Technol 2002, 17 (1), 14-18, DOI: 10.1007/BF02852625 